\title{
Cardiac magnetic resonance imaging for comprehensive assessment of bicuspid aortic valve: comparison with transthoracic echocardiography, dual-source $\mathrm{CT}$ and operative findings
}

\author{
SungMin Ko \\ From 2011 SCMR/Euro CMR Joint Scientific Sessions \\ Nice, France. 3-6 February 2011
}

\section{Introduction}

Patients with bicuspid aortic valve (BAV) are at increased risk for both valvular and vascular complications. Preoperative knowledge about AV morphology, the presence and extent of AV and annulus calcification, valvular complications, and ascending aorta (AA) diameter is very important for surgical planning in patients with BAV.

\section{Purpose}

To evaluate the value of cardiac magnetic resonance imaging (CMR) for the comprehensive assessment BAV in comparison with transthoracic echocardiography (TTE), dual-source computed tomography (DSCT), and operative findings.

\section{Methods}

Seventy-three consecutive patients (49 men, mean age 51.2 years) with BAV who underwent TTE, DSCT, cardiac MRI and valve surgery were enrolled in this study. All CMR studies were performed with a $1.5 \mathrm{~T}$ whole-body system using an 8-element phased array surface coil. Two independent radiologists assessed the type of BAV (classified according to number of raphe), functional status of the BAV, AA diameter and left ventricular ejection fraction (LVEF). Stenotic aortic valve area (AVA) was computed with the continuity equation on TTE and by direct planimetry on DSCT and CMR. We compared quantitative grading of aortic regurgitation (AR) by CMRI with semiquantitative grading of AR by TTE. AA diameter was measured at 4 levels from mid-systole on DSCT and CMR. LVEF by CMR (Simpson's method) was compared with the use of TTE (M-mode method).

\section{Results}

Patients underwent AV repair $(\mathrm{n}=72)$ or replacement $(\mathrm{n}=1)$ with AA graft replacement $(\mathrm{n}=3)$ or wrapping $(n=28)$. CMR showed $91.8 \%$ agreement of BAV type compared with operative findings [no raphe $(n=30)$ and raphe $(n=43)]$. CMR showed excellent agreement $(\kappa=0.954)$ of the underlying BAV complications as compared with TTE [regurgitation $(\mathrm{n}=21)$, stenosis $(\mathrm{n}=27)$, and mixed $(n=24)]$. Stenotic AVA $(n=51)$ by CMR $(0.88$ $\left.\pm 0.29 \mathrm{~cm}^{2}\right)$ correlated well with AVA by DSCT $(1.04$ $\left.\pm 0.30 \mathrm{~cm}^{2}, r=0.84, p<0.0001\right)$ and TTE $\left(0.82 \pm 0.25 \mathrm{~cm}^{2}\right.$, $r=0.75, p<0.0001$ ). Regurgitation grading by CMR was significantly correlated with the grading of AR severity by TTE $(\mathrm{n}=45, r=0.85, p<0.0001)$. AA dilatation more than $4.5 \mathrm{~cm}$ in diameter was present in $30(41 \%)$ patients. There was excellent correlation $(r=0.98$, $p<0.0001)$ in the mean diameter of AA between DSCT and CMR $(35.0 \pm 8.1 \mathrm{~mm}$ vs $35.2 \pm 8.0 \mathrm{~mm}, p=0.061)$. A moderate correlation between CMR and TTE was shown for the evaluation of LVEF $(56.2 \pm 10.2 \%$ vs 62.3 $\pm 12.4 \%$, respectively; $r=0.63$ ).

\section{Conclusions}

CMR allows accurate imaging technique for comprehensive assessment of patients with BAV. 
Cite this article as: Ko: Cardiac magnetic resonance imaging for comprehensive assessment of bicuspid aortic valve: comparison with transthoracic echocardiography, dual-source $\mathrm{CT}$ and operative findings. Journal of Cardiovascular Magnetic Resonance 2011 13(Suppl 1):P339.

Submit your next manuscript to BioMed Central and take full advantage of:

- Convenient online submission

- Thorough peer review

- No space constraints or color figure charges

- Immediate publication on acceptance

- Inclusion in PubMed, CAS, Scopus and Google Scholar

- Research which is freely available for redistribution

Submit your manuscript at www.biomedcentral.com/submit
Ciomed Central 